ISSN 1984-3372

http://portaldeperiodicos.unisul.br/index.php/EeN/index

\title{
NANOTECNOLOGIA: INOVAÇÃO PARA A COMPETITIVIDADE NA CADEIA PRODUTIVA TÊXTIL BRASILEIRA
}

\section{NANOTECHNOLOGY: INNOVATION FOR COMPETITIVENESS IN BRAZILIAN TEXTILE PRODUC- TION CHAIN}

\section{NANOTECNOLOGÍA: INNOVACIÓN PARA VENTAJAS COMPETITIVAS EM LA CADENA PRO- DUCTIVA TEXTIL BRASILEÑA}

\author{
Adilson Caldeira \\ Professor do Centro de Ciências Sociais e Aplicadas (CCSA) da Universidade Presbiteriana Mackenzie \\ Doutor em Administração de Empresas pela Universidade Presbiteriana Mackenzie \\ Endereço: R. da Consolação, n. 896, Prédio 60,Consolação, CEP 01302-907. São Paulo, SP, Brasil \\ Telefone: (011) 2114-8140. E-mail: adilson.caldeira@mackenzie.br
}

\section{Ana Cristina Bachur Silva}

Bacharela em Administração e pesquisadora vinculada ao NEPEI - Núcleo de Estuudos e Pesquisa em Estratégia e Inovação da Universidade Presbiteriana Mackenzie Endereço: R. da Consolação, n. 896, Prédio 60,Consolação, CEP 01302-907. São Paulo, SP, Brasil Telefone: (011) 2114-8140. E-mail: anacristinabachur@gmail.com

\section{Elis Aniceto}

Bacharela em Administração e pesquisadora vinculada ao NEPEI - Núcleo de Estudos e Pesquisa em Estratégia e Inovação da Universidade Presbiteriana Mackenzie

Endereço: R. da Consolação, n. 896, Prédio 60,Consolação, CEP 01302-907. São Paulo, SP, Brasil

Telefone: (011) 2114-8140. E-mail: elisaniceto@hotmail.com>

\section{Camila Marinho Borba}

Bacharela em Administração e pesquisadora vinculada ao NEPEI - Núcleo de Estudos e Pesquisa em Estratégia e Inovação da Universidade Presbiteriana Mackenzie

Endereço: R. da Consolação, n. 896, Prédio 60,Consolação, CEP 01302-907. São Paulo, SP, Brasil

Telefone: (011) 2114-8140. E-mail: cmborba@outlook.com

\section{Caroline Petruz}

Bacharela em Administração e pesquisadora vinculada ao NEPEI - Núcleo de Estudos e Pesquisa em Estratégia e Inovação da Universidade Presbiteriana Mackenzie

Endereço: R. da Consolação, n. 896, Prédio 60,Consolação, CEP 01302-907. São Paulo, SP, Brasil

Telefone: (011) 2114-8140. E-mail: ca_petruz@hotmail.com

Artigo recebido em 07/12/2015. Revisado por pares em 14/11/2015. Reformulado em 08/12/2015. Recomendado para publicação em 20/12/2015 por Ademar Dutra (Editor Científico). Publicado em 30/12/2015. Avaliado pelo Sistema double blind review.
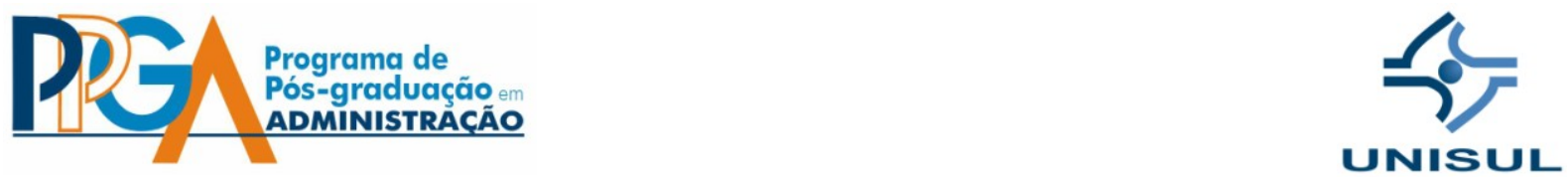


\section{RESUMO}

Este estudo exploratório de caráter qualitativo tem por objetivo conhecer as potenciais contribuições da inovação, via nanotecnologia, à competitividade da indústria têxtil brasileira. A partir de um aporte teórico que aborda os temas Inovação, Competitividade e Nanotecnologia, construiu-se um roteiro de questões direcionador de entrevistas realizadas com profissionais que atuam e conhecem o setor focalizado na pesquisa. Os resultados revelam que a indústria têxtil internacional está em processo de expansão, a inovação é considerada um meio essencial para a competitividade, e a nanotecnologia é vista como potencial agente de agregação de valor aos produtos e processos produtivos.

Palavras-chave: Nanotecnologia; Inovação; Indústria Têxtil; Competitividade.

\section{ABSTRACT}

This qualitative exploratory study aims to understand the potential contributions of innovation via nanotechnology to Brazilian textile industry competitiveness. A theoretical approach that addresses to the topics Innovation, Competitiveness and Nanotechnology has built up a roadmap for driver issues interviews with professionals who actuate and know the focused industry. Results reveal that international business in textile industry increases, innovation is considered an essential way for competitiveness and nanotechnology is seen as a potential agent of adding value to products and production processes.

Keywords: Nanotechnology; Innovation; Textile Industry; Competitiveness.

\section{RESUMEN}

Este estudio exploratorio cualitativo tiene por objetivo conocer potenciales contribuciones de la innovación por medio de la nanotecnología para ventajas competitivas de la industria textil brasileña. Desde un aporte teórico que aborda los temas Innovación, Ventajas Competitivas y Nanotecnología fue construido un guion de cuestiones para direccionar entrevistas realizadas con profesionales que actúan y conocen el sector focalizado en la investigación. Los resultados revelan que la industria textil internacional está en proceso de expansión, la innovación es considerada un medio esencial para la competitividad, y la nanotecnología es mirada como potencial agente de agregación de valor a los productos y procesos productivos.

Palabras-clave: Nanotecnología; Innovación; Industria Textil; Ventajas competitivas. 


\section{INTRODUÇÃO}

O ritmo evolutivo acelerado determinado pelo caráter dinâmico das mudanças decorrentes de novas tecnologias, necessidades e exigência dos consumidores coloca países, empresas e indivíduos diante da ambígua condição de se encontrarem diante de oportunidades de desenvolvimento e, ao mesmo tempo, de desafios de adaptação contínua a novas condições de competitividade.

Esse é o quadro observado atualmente no Brasil, considerado um país com potencial de desenvolvimento desafiado pela necessidade de conquistar e manter a capacidade competitiva no cenário internacional. Considerando o Índice de Competitividade Mundial da escola suíça IMD, o país vem caindo no ranking de competitividade de forma acelerada, pois no período entre 2010 e 2014 foi do 38 para o 54ㅇ lugar em uma lista de 60 países. A mesma pesquisa revela que um dos fatores de peso para tamanho retrocesso foi a perda de participação no mercado internacional: o Brasil realizou a menor Taxa de Comércio internacional e a segunda menor Taxa de Exportação, avaliadas pelo PIB, dentre os 60 participantes da pesquisa (FOLHA, 2015).

Os indicadores da pesquisa revelam que, embora tenha conseguido manter-se em crescimento e atraindo investimentos em um período de crise econômica que atingiu proporções mundiais nos últimos anos, o Brasil possui uma economia de forte demanda, em que o consumo é mais valorizado do que a produção, de forma que não são priorizados investimentos em capacitação competitiva (BBC, 2015).

Por outro lado, a magnitude do parque produtivo brasileiro revela potencial para que essa situação seja revertida. É o caso da indústria têxtil e de confecções, que realizou um faturamento de US\$ 53 bilhões no ano de 2013, figurando como a quinta maior produtora têxtil e contando com o quarto maior parque produtivo de confecção do mundo. O setor é segundo maior empregador da indústria de transformação brasileira, oferecendo 16,4\% dos empregos, perdendo apenas para o de alimentos e bebidas (TEXBRASIL, 2015). Estes dados revelam o potencial que o setor tem para contribuir com o desenvolvimento da competitividade do país. 
O cenário da crise do setor têxtil brasileiro tornou-se foco de diversos estudos acadêmicos, tecnológicos e políticos, com o objetivo de trazer a recuperação do setor no mercado internacional. Para isso, grande parte dos estudos é focada na inovação e nos benefícios que esta pode trazer para toda a cadeia produtiva.

A cadeia têxtil brasileira é representada pela Associação Brasileira da Indústria Têxtil, conhecida como ABIT, esta visa a atender todas as demandas da cadeia e dos seus associados, desde as empresas produtoras de fibras químicas, sintéticas e artificiais, fiações, beneficiadoras, tecelagens, confeç̧ões e o varejo. O departamento de Infraestrutura e Capacitação Tecnológica da ABIT defende uma estratégia que deve procurar a diferenciação do produto, buscando inovação e criatividade em relação à marca e ao design brasileiro, para agregar maior valor ao produto.

Dentre os setores mais inovadores da cadeia produtiva têxtil destaca-se o atacadista da moda. Mesmo assim, não é comum observar, nesse setor, inovações tecnológicas de impacto. Ao contrário, "grande parte das inovações é incremental, e a imitação criativa é bastante comum, apesar de haver espaços para tentativas de invenções de produtos" (DE OLIVEIRA; EPAMINONDAS, 2014, p. 83).

Em busca de fontes mais radicais de inovação, um dos focos da ABIT direciona-se para a nanotecnologia e importação de novas tecnologias para gerar produtos diferenciados, que façam concorrência com os produtos estrangeiros, em especial produtos da China, o maior concorrente brasileiro (ABIT, 2015).

O mercado internacional tem, atualmente, por volta de 800 produtos de consumo com nanotecnologia, que resultam da manipulação de partículas 100000 vezes mais finas que um fio de cabelo. Estes vão desde tecidos impermeáveis, tintas resistentes a riscos até cosméticos anti-idade. Com a perspectiva de um mercado tão grande, existe a possibilidade de as empresas reconquistarem seu espaço internacional através da nanotecnologia, apesar das dificuldades encontradas no Brasil, onde a inexistência de regulamentação faz com o que o governo não consiga decidir o que é bom ou não para o consumidor. Isto traz ao país o risco de ficar apenas com as migalhas de um mercado tão grande e em desenvolvimento como este (EXAME, 2015). 
Em vista da situação do desenvolvimento da nanotecnologia no país, criou-se recentemente a Iniciativa Brasileira de Nanotecnologia (IBN), com o objetivo de "criar, integrar e fortalecer as atividades governamentais e os agentes ancorados na nanociência e nanotecnologia, para promover o desenvolvimento científico e tecnológico do setor, com foco na inovação" (MCTI, 2015).

Diante desse contexto, a inquietação que conduziu ao presente estudo principia pela possibilidade de aproveitamento de novos recursos provenientes do desenvolvimento da nanotecnologia, no favorecimento das condições de competitividade do setor têxtil no cenário internacional. O problema de pesquisa que se adota como referência é: Quais contribuições a nanotecnologia pode trazer à indústria têxtil brasileira como forma de inovação para o aumento de competitividade? Como objetivo geral, portanto, busca-se conhecer as possíveis contribuições que a nanotecnologia pode trazer à indústria têxtil brasileira como forma de inovação e aumento da competitividade.

Para atingir o objetivo, estabeleceram-se os objetivos específicos de: a) identificar as características da indústria têxtil no Brasil, suas oportunidades e dificuldades; b) conhecer a principal necessidade de inovação na indústria têxtil; c) analisar as diferentes maneiras de uma empresa têxtil obter competitividade no mercado; e d) compreender o desenvolvimento da nanotecnologia do mercado nacional e internacional no setor têxtil.

\section{REFERENCIAL TEÓRICO}

\subsection{OS DESAFIOS DA COMPETITIVIDADE}

A competitividade é considerada um desafio que se apresenta, na atualidade, em âmbito global. As razões que levaram à expansão da competitividade nesse último século, em um ritmo mais acelerado que antes, estão ligadas ao acirramento da concorrência entre empresas em todos os mercados, e em uma escala global. Na atualidade, "o ambiente competitivo é caracterizado pela globalização e pelos avanços rápidos na tecnologia" (HOSKISSON et. al., 2010, p. 28).

Porter (2003) sustenta que as empresas conquistam vantagens em relação aos concorrentes em função das pressões e dos desafios, favorecendo-se da existência de rivais, de 
uma base de fornecedores agressivos e de clientes exigentes. Para Hitt, Ireland e Hoskinsson (2015), existe competitividade quando duas ou mais organizações contrapõem-se na busca de uma posição vantajosa de mercado. Quando firmas diferem entre si em termos de recursos, capacidades e competências essenciais e em termos de oportunidade e ameaças em suas indústrias e em seus ambientes competitivos, surge a rivalidade competitiva, ou seja, uma situação de assimetria competitiva conduz à rivalidade competitiva. Como decorrência, os gestores são desafiados a adotar uma mentalidade administrativa que valorize a flexibilidade, velocidade, inovação e integração para que a empresa obtenha competitividade estratégica.

Hoskisson et. al. (2010, p. 3) propõem que "a vantagem competitiva surge da formulação e da execução bem-sucedidas de estratégias que são distintas e criam mais valor que as estratégias dos concorrentes". Conforme se observa, as respostas das empresas aos desafios da competitividade traduzem-se em estratégias para a construção de vantagens competitivas.

Barney e Hesterly (2011, p. 9) destacam que, "em geral, uma empresa possui vantagem competitiva quando é capaz de gerar maior valor econômico do que suas concorrentes".

Como meio para a geração de vantagem competitiva, Porter $(2003$, p. 39) destaca o papel da tecnologia e da inovação. Segundo o autor, "o desenvolvimento da tecnologia é importante para a vantagem competitiva em todas as indústrias, sendo vital em algumas". Ainda segundo Porter (2003, p. 2), a competitividade depende da capacidade de inovação e melhorias de um dado setor de atividade, sendo que a vantagem competitiva surge, basicamente, "[...] do valor que uma empresa consegue criar para seus compradores e que ultrapassa o custo de fabricação pela empresa. O valor é aquilo que os compradores estão dispostos a pagar [...] compensam um preço mais alto".

Em consonância com essa visão, Bateman e Snell (2007) assumem o pressuposto de que a inovação é necessária para que as organizações consigam adaptar-se às mudanças na demanda dos consumidores e novos concorrentes. Por sua vez, Hamel e Prahalad (2002) afirmam que, nos últimos anos, em um ambiente de competição, os novatos vêm levando 
vantagem sobre os veteranos com novas abordagens não convencionais para os negócios. Mesmo assim, os veteranos que continuam inovando conseguem se sustentar no mercado. Wright, Kroll e Parnell (2007) adicionam que a vantagem competitiva pode ser adquirida com inovações em produto, modificando os atributos ou a forma como ele é percebido pelos consumidores; e em processo, fazendo uso de atividades que aumentam a eficiência das operações e da distribuição.

A partir de visões como essas, depreende-se que a capacidade de inovação é apontada como elemento intrínseco à competitividade em diversos estudos constantes na literatura especializada. No item seguinte abordam-se, de forma mais ampla, aspectos relativos ao papel da inovação na competitividade das empresas.

\subsection{INOVAÇÃO COMO FONTE DE COMPETITIVIDADE}

Govindarajan e Trimble (2010) destacam necessidade de atenção dos gestores para a importância das inovações, considerando-as fator crítico de sucesso competitivo. Essa visão é compartilhada por Sparrow (2010), que enaltece a necessidade de uma cultura voltada para a inovação, e também por Bowonder et al. (2010), que associam as estratégias baseadas na inovação à conquista de vantagem competitiva.

Na visão de Tidd, Bessant e Pavitt (2008, p. 85), a inovação "é mais do que simplesmente conceber uma nova ideia; é o processo de desenvolver seu uso prático". Segundo os mesmos autores, além do foco na abertura de novos mercados, a inovação também pode significar novas formas de servir a mercados já estabelecidos e maduros. Essa afirmação pressupõe que as tendências mudam, e que os próprios consumidores exigem mudanças em períodos menores de tempo. Então, a questão não é apenas criar sempre algo que nunca existiu, mas manter e aperfeiçoar algo já existente para, assim, criar competitividade no mercado, além de fidelizar clientes, considerando, ainda, a pesquisa e o desenvolvimento necessários em toda a cadeia produtiva e todo o ambiente organizacional (TIDD; BESSANT; PAVITT, 2008).

A referência mundial aos conceitos e definições mais utilizados para os processos de inovação é o Manual de Oslo, desenvolvido pela OCDE, com o intuito de ampliar o conteúdo do Manual de Frascati, que se limitava ao estudo das atividades de pesquisa e desenvolviRevista Eletrônica de Estratégia \& Negócios, Florianópolis, v.8, n.3, set./dez. 2015. 
mento (P\&D) (TIGRE, 2006). Tidd, Bessant e Pavitt (2008, p. 30) propõem que a inovação pode ser de produto, processo, posição e paradigma, que se caracterizam pelos " 4 P's da inovação". A inovação de produto caracteriza-se pela mudança em produtos e serviços oferecidos. A de processo representa mudança na forma em que os produtos e serviços são criados e entregues. Já a inovação de posição caracteriza-se por mudanças no contexto em que os produtos e serviços são introduzidos, enquanto a inovação de paradigma materializase por mudanças nos modelos mentais que orientam o que a empresa faz (TIDD; BESSANT; PAVITT, 2008).

Com a inovação, novos produtos surgem e outras fatias do mercado são alcançadas ou criadas, aumentando, então, sua lucratividade. Assim sendo, novos produtos e serviços são mecanismos importantes para manter a empresa competitiva. Para isso, um dos grandes papéis dos gestores é identificar os consumidores inovadores, ou seja, aqueles que são os primeiros a adquirir o novo produto ou serviço, pois são esses que definem o sucesso ou fracasso da inovação (TIDD; BESSANT; PAVITT, 2008).

Provavelmente pela expressiva contribuição ao desempenho competitivo das empresas, a inovação tecnológica vem sendo alvo de grande parte das pesquisas registradas nos últimos anos na literatura científica brasileira (VENÂNCIO; ANDRADE; FIATES, 2014). No tópico seguinte abordam-se, de forma mais aprofundada, os aspectos relativos à importância da inovação tecnológica, segundo essa literatura.

\subsubsection{A importância da inovação tecnológica}

A introdução do termo inovação tecnológica foi feita primeiramente nos anos 60 , por meio da elaboração do Manual Frascati, que consolidou os conceitos e definições sobre as atividades empresariais de Pesquisa e Desenvolvimento, além de permitir a criação de sistemas de indicadores de desempenho tecnológicos. Esse manual foi uma iniciativa da Organização para Cooperação e Desenvolvimento Econômico (OCDE) para desenvolvimento econômico e social (TIGRE, 2006).

As inovações tecnológicas, para Tigre (2006), podem ser classificadas segundo seus impactos na empresa e no mercado. De acordo com essa classificação, as inovações podem 
se caracterizar como incrementais, radicais, como novo sistema tecnológico ou novo paradigma tecnoeconômico, cujas características se apresentam no quadro 1.

Quadro 1 - Taxonomia das mudanças tecnológicas

Tipo de mudança Características

\begin{tabular}{ll}
\hline Incremental & Melhoramento e modificações cotidianas \\
\hline Radical & Saltos descontínuos na tecnologia de produtos e processos \\
\hline Novo sistema tecnológico & Mudanças abrangentes que afetam mais de um setor e \\
& dão origem a novas atividades econômicas \\
\hline Novo paradigma tecnoeconômico & Mudanças que afetam toda a economia envolvendo mu- \\
& danças técnicas e organizacionais, alterando produtos e \\
& processos, criando novas indústrias e estabelecendo traje- \\
& tórias de inovações por várias décadas
\end{tabular}

Fonte: Tigre (2006, p. 74).

A inovação tecnológica integra a aplicação do conhecimento à economia, no mercado e na sociedade. A capacidade permanente de inovação tecnológica é uma condição que gera a sustentabilidade da competitividade de um país. Os fatores que induzem a uma mudança tecnológica são dois: as necessidades explicitadas pelo mercado e seus consumidores (demand-pull), e os avanças autônomos da ciência e tecnologia que independem da empresa por si só (technology push) (TIGRE, 2006).

Segundo Porter (2003, p. 17), "a introdução de uma inovação tecnológica importante pode permitir que uma empresa reduzisse o custo e intensifique a diferenciação simultaneamente, e talvez alcance ambas as estratégias". A introdução de uma nova tecnologia é entendida como a trajetória de adoção e aceitação de uma tecnologia no mercado.

A difusão da tecnologia possui quatro fases distintas: (1) introdução - número pequeno de usuários adota a tecnologia; (2) crescimento - aumento do sucesso e melhoria progressiva do desempenho; (3) maturação - as vendas estabilizam e inovações incrementais diminuem; (4) declínio - usuários deixam de usar essa tecnologia graças ao aparecimento de outra (TIGRE, 2006).

Revista Eletrônica de Estratégia \& Negócios, Florianópolis, v.8, n.3, set./dez. 2015. 


\subsubsection{A nanotecnologia como fonte de inovação e competitividade}

Construir ferramentas para dominar o meio em que vive é uma característica presente na história da evolução humana. Esse domínio corresponde à tecnologia, a qual pode ser descrita como o estudo racional dos fenômenos desvendados pelo homem, com a finalidade de apresentar soluções lucrativas a serem colocadas no mercado (TOMAS, 2009).

O termo nano, que deriva de anão, é um prefixo de origem grega adotado na ciência para designar uma parte em um bilhão, de forma que um nanômetro ( $1 \mathrm{~nm}$ ) equivale a um bilionésimo de um metro. A nanociência e a nanotecnologia lidam com o estudo e a aplicação de materiais em nano escala em diversos campos da ciência, tais como Química, Biologia, Física, Ciência dos Materiais e Engenharia. A nanotecnologia representa a habilidade de trabalhar em nível atômico, resultando em estruturas maiores (nanoestruturas) de organização molecular mais definida (COUTO, 2006).

Pesquisas como as de Buzby (2010), Stampfli, Siegrist e Kastenholz (2010), Doering (2011), Erdogan (2011), Khadzhiev (2011) e Festel e Kratzer (2012) registram aplicações da nanotecnologia e seus benefícios ao desempenho de empresas de diferentes setores de atividade produtiva no cenário econômico internacional. Já Maine, Lubik e Garnsey (2012) constataram os benefícios à cadeia de valor, conquistados por empresas de diferentes setores, que investiram em inovações provenientes do desenvolvimento e aplicação da nanotecnologia a seus produtos e processos.

Seguindo essa tendência mundial, a indústria brasileira já se beneficia da nanotecnologia em diversas áreas de aplicação, desde os nano compósitos poliméricos, produzidos a partir de commodities, como os termoplásticos e as argilas, ao lado de produtos fabricados em quantidades reduzidas, mas com elevado valor agregado e criados para as tecnologias de informação e de telecomunicações (GRUPO DE TRABALHO, 2015).

Levando em conta os avanços da nanotecnologia e as possibilidades que esta pode trazer como fonte de inovação para aumento da competitividade de empresas no mercado doméstico e internacional, discutem-se, no próximo item, as características da indústria têxtil e como esta pode ser beneficiada pela nanotecnologia. 


\section{A INDÚSTRIA TÊXTIL BRASILEIRA E SEUS DESAFIOS COMPETITIVOS}

O setor industrial têxtil e de confecções destaca-se pela tradição e pela expressiva participação na economia mundial, abrangendo um grande número de empresas em sua cadeia produtiva. Conforme se apresenta na Figura 1, a cadeia produtiva têxtil tem início na agropecuária, com a produção de fibras naturais, ou na indústria química, em que se originam as matérias primas para a produção de fibras artificiais e sintéticas. A produção de fios (fiação) representa o elo seguinte dessa cadeia, sucedido pelo de tecelagens, em que se fabricam os tecidos planos, ou malharias. Em seguida, há o elo em que ocorre o beneficiamento e acabamento, e então o elo em que se realiza a confecção dos produtos finais, em forma de vestuário ou de artigos para uso doméstico, em decoração ou outras aplicações. Os produtos finais também podem se destinar à utilização industrial, sob a forma de tecidos técnicos como, por exemplo, filtros, componentes para o interior de automóveis ou embalagens (COSTA; ROCHA, 2009).

Figura 1 - Cadeia Produtiva Têxtil

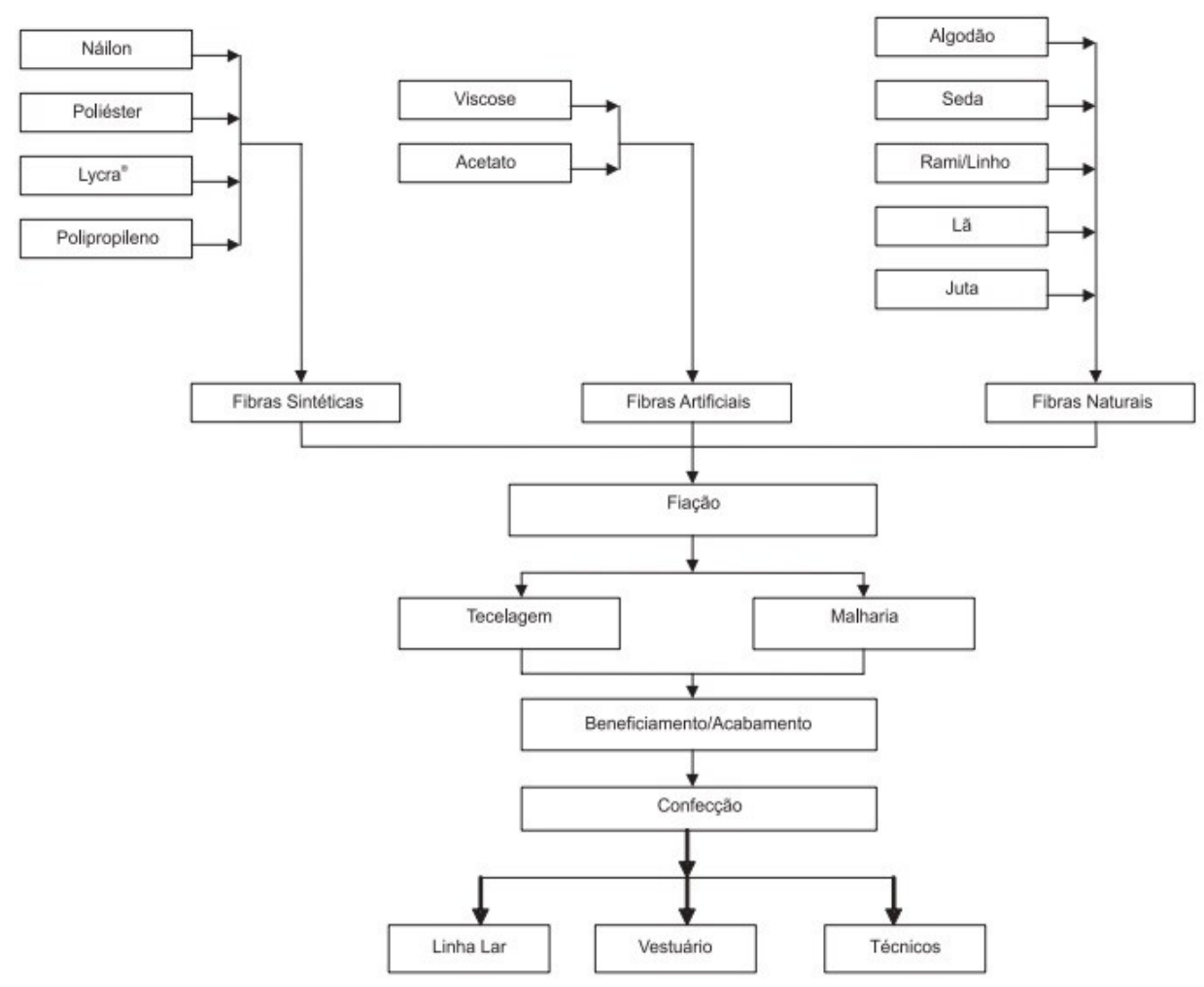

Revista Eletrônica de Estratégia \& Negócios, Florianópolis, v.8, n.3, set./dez. 2015. 
Fonte: Costa e Rocha (2009).

No Brasil, o setor têxtil está presente há mais de 200 anos e desempenha papel de destaque no desenvolvimento econômico e social. A própria diversidade determinada pela extensão territorial e a variedade cultural de cada região brasileira desafiam as empresas a criar e desenvolver capacidade de se diferenciar por intermédio de inovação nos meios de produção e tratamento dos tecidos (DE OLIVEIRA; EPAMINONDAS, 2014).

A cadeia têxtil brasileira é completa, com empresas que atuam desde a plantação de algodão e produção de fibras sintéticas, até aos desfiles de moda, passando por fiações, tecelagens, beneficiadoras, confecções e comércio atacadista e varejista. Segundo ABIT (2015), o país é referência mundial em design de moda praia, jeanswear e homewear, tendo crescido também os segmentos de fitness e lingerie. A cadeia têxtil brasileira conta com 30 mil empresas formais, gera 1,7 milhão de empregos diretos e 8 milhões indiretos, que representam $16,4 \%$ dos empregos do país. O setor é responsável por 5,5\% do faturamento da indústria de transformação e figura como quarto maior parque produtivo de confecção e quinto maior produtor têxtil do mundo (TEXBRASIL, 2015).

Contudo, esse desempenho não proporciona uma posição competitiva favorável, considerando os dados históricos e evolutivos. Conforme destacam Melo et al. (2007), até a década de 1980, a indústria têxtil brasileira era detentora de um mercado interno cativo, fechado às importações de produtos acabados, de insumos e equipamentos. A ausência de concorrência nesse período causou acomodação nas empresas nacionais, que não acompanharam o processo de modernização dos demais países. Gerou-se, assim, uma lacuna tecnológica em relação ao restante do mundo.

No início dos anos 1990, as principais barreiras protecionistas legais contra a importação foram retiradas, expondo as empresas do setor têxtil a um novo padrão de concorrência. Em meio ao árduo esforço demandado para o reposicionamento em busca da recuperação da competitividade em termos globais, muitas empresas não resistiram e encerraram suas atividades, enquanto o setor via-se obrigado a promover um esforço concentrado para investir na criação de condições para competir com os produtos importados (MELO et al., 2007).

Revista Eletrônica de Estratégia \& Negócios, Florianópolis, v.8, n.3, set./dez. 2015. 
Desde o início do terceiro milênio, a cadeia produtiva têxtil sofre com o ritmo acelerado de mudanças a partir de novas tecnologias e condições de mercado, observando um novo padrão de concorrência. Países periféricos como Índia, Indonésia, Hong Kong e Taiwan estabeleceram um novo padrão em que a concorrência deixou de se limitar a preços para agregar aspectos como qualidade, flexibilidade e diferenciação, além da redução significativa de custos decorrente da utilização de mão de obra barata destes locais (COSTA; ROCHA, 2009).

Na opinião de Melo et al. (2007), o cenário atual do setor têxtil caracteriza a competitividade pela capacidade das empresas em produzir e entregar artigos diferenciados e cada vez mais complexos, no menor tempo possível. Para contrapor a concorrência dos países mais desenvolvidos, as empresas buscam inovações tecnológicas ao nível da cadeia (aplicação de técnicas de supply chain management na cadeia têxtil e de confecções), produtos (ampliação do conteúdo tecnológico) e processos (automação e escala); inovações mercadológicas; especialização em segmentos mais intensivos em capital dentro de cada elo; e entre elos, transferência de processos menos eficientes para países vizinhos (ABIT, 2003).

Com o desafio determinado pela possível escassez de produtos naturais, assim como novas necessidades e desejos dos consumidores, seja para benefícios ao conforto e saúde ou para acompanhar a efemeridade da moda, que movimenta e alimenta esse setor, surgiram roupas com recursos tecnológicos que possibilitam, por exemplo, monitorar os batimentos cardíacos, proteger de raios ultravioletas, preservar a hidratação, beneficiar a respirabilidade e o controle de transpiração da pele e estimular a microcirculação (MOREIRA; FANGUEIRO; LEAL, 2012).

Ou seja, a tecnologia já oferece à indústria alguns meios de qualificar e melhorar as propriedades naturais dos tecidos, como as fibras artificiais e muitos tipos de beneficiamento (UDALE, 2009). Todavia, é no estudo sobre nanotecnologia onde se encontra a linha de pesquisa mais recente do setor (COLCHESTER, 2008). Ela consiste na investigação microscópica das partes em nível atômico, molecular ou supramolecular para entender as propriedades e características de suas estruturas e, assim, possibilitar o desenvolvimento de novas composições mais eficientes (DURAN; MATTOSO; MORAIS, 2006). 
Segundo destacam Wong et al. (2014), a nanotecnologia supera as limitações da aplicação de métodos convencionais para conferir mais propriedades aos materiais têxteis. Os autores sustentam que não há dúvida de que, nos próximos anos, a nanotecnologia vai permear todas as áreas da indústria têxtil. Atualmente, já se conta com a nanotecnologia para a melhoria de propriedades dos tecidos. Por exemplo, a propriedade repelente de água é beneficiada com a utilização de hidrocarbonetos com um milésimo do tamanho de uma fibra de algodão típico, adicionando-os ao tecido para criar um efeito aveludado sem reduzir a força de algodão. Outra aplicação já conhecida é a utilização de óxido de zinco e dióxido de titânio em partículas de tamanho "nano", comprovadamente mais eficientes na absorção e dispersão de radiação ultravioleta (UV). Também já se utiliza a nanotecnologia para conferir propriedades antibacterianas, fungicidas, anti-estáticas e antirrugas, com a aplicação de partículas nano de prata, dióxido de titânio e óxido de zinco ou sílica, por exemplo (WONG et al., 2014).

\section{PROCEDIMENTOS METODOLÓGICOS}

Este estudo possui caráter qualitativo com propósito exploratório, tendo como objetivo conhecer as possíveis contribuições que a nanotecnologia pode trazer à indústria têxtil brasileira como forma de inovação e aumento da competitividade. A utilização de pesquisa dessa natureza é mais adequada quando se busca compreender um fenômeno social, pois ela apresenta menos limitações do que a pesquisa quantitativa (GODOY, 1995).

Como estratégia de coleta de dados optou-se por utilizar entrevistas semiestruturadas, com gestores considerados conhecedores e atuantes em atividades profissionais relativas ao tema. A quantidade de entrevistas foi determinada tomando, por referência, a proposta de Johnson (2002), segundo a qual o número ideal é o quanto os pesquisadores entendam ser suficiente para descobrir o que busca, com a possibilidade de retornar à abordagem de alguns dos informantes que, aparentemente, detenham maior conhecimento sobre um assunto específico de uma determinada categoria. Seguindo essa orientação, foram escolhidos cinco sujeitos considerados preparados para fornecer as informações desejadas: um executivo da Associação Brasileira da Indústria Têxtil; com uma pesquisadora e docente que atua no ensino superior ministrando disciplinas relativas à Tecnologia Têxtil e de Documentação Técnica na Moda; com um químico Industrial e Revista Eletrônica de Estratégia \& Negócios, Florianópolis, v.8, n.3, set./dez. 2015. 
responsável por Negócios de Acabamentos Têxteis; com um Engenheiro Têxtil; e com um executivo que atua na gestão de uma empresa internacional presente em diferentes elos da cadeia produtiva têxtil, com operações de fabricação de tecidos especiais, acabamento em fios, tecidos, artefatos têxteis e peças do vestuário, além de atuar no comércio atacadista de tecidos.

Visando à preservação da identidade dos entrevistados, atribuiu-se a cada um deles um código de entrevistado, conforme se apresenta no quadro 2.

Quadro 2 - Sujeitos da Pesquisa

Entrevistado

Especialidade

\begin{tabular}{cc}
\hline E1 & Executivo da Associação Brasileira da Indústria Têxtil \\
\hline E2 & Docente de Tecnologia Têxtil e de Documentação Técnica na Moda \\
\hline E3 & Químico Industrial e responsável por Negócios de Acabamentos Têxteis \\
\hline E4 & Engenheiro Têxtil \\
\hline E5 & Executivo de Fábrica Têxtil \\
\hline
\end{tabular}

Fonte: Elaborado pelos autores (2015).

Tomando como principais direcionadores o problema de pesquisa e os objetivos estabelecidos para o trabalho, elaborou-se um roteiro que permitisse conferir à entrevista um caráter semiestruturado. Seguindo a sugestão de Flick (2009, p. 118), para quem "o elemento central dessa forma de entrevista é o convite periódico à apresentação de narrativas de situações", elaborou-se um roteiro composto de dez questões abertas, formuladas a partir de conceitos obtidos na literatura e que fundamentaram os pressupostos conceituais assumidos no referencial teórico deste trabalho.

As entrevistas foram transcritas na íntegra, e o contexto original do momento da entrevista foi preservado nas transcrições de detalhes nas respostas dos entrevistados. Para análise dos dados recorreu-se à técnica de análise de conteúdo proposta por Bardin (2007) 
que, segundo a referida autora, tem como objetivo principal fornecer, de forma consolidada, uma interpretação dos dados brutos obtidos para que os mesmos sejam transformados em dados organizados. Trata-se de uma operação de classificação dos elementos característicos de um conjunto, que se diferenciam e, em seguida, reagrupam-se segundo critérios previamente definidos. Bardin (2007) emprega dois processos inversos para a categorização: o primeiro processo desenvolve-se quando já é fornecido o sistema de categorias. Sendo assim, os elementos são repartidos da melhor maneira possível em duas respectivas categorias. O outro processo seria o oposto, quando ainda não foi fornecido o sistema de categorias, antes resultando da classificação analógica e progressiva dos elementos.

Bardin (2007, p. 113) percebe que, "geralmente as categorias terminais provêm do reagrupamento progressivo de categorias com uma generalidade mais fraca". Com isso, a análise utilizada para este estudo busca apoio no segundo processo citado anteriormente, quando ainda não se apresenta o sistema de categorias.

Esclarecidos os procedimentos para coleta e análise dos dados, apresenta-se, a seguir, a discussão dos resultados obtidos.

\section{APRESENTAÇÃO E ANÁLISE DOS DADOS}

Nos itens seguintes apresenta-se a análise resultante dos dados obtidos a partir da pesquisa de campo realizada.

\subsection{OS RUMOS DA INDÚSTRIA TÊXTIL BRASILEIRA}

Os entrevistados apontaram, como principal oportunidade da Indústria têxtil brasileira, a vontade de conferir a esse setor maior competitividade em âmbito global. Essa preocupação reflete a visão de Hoskisson et al. (2010), sobre a aceleração do ritmo na busca por competitividade, e a rapidez do avanço da tecnologia face ao acirramento da concorrência em escala global.

Essa opinião também segue os pressupostos de Melo et al. (2007) sobre a sucessiva perda de competitividade do setor, como um desafio à adoção de estratégias que conduzam 
ao desenvolvimento da capacidade das empresas em produzir e entregar artigos diferenciados e cada vez mais complexos, no menor tempo possível.

Os entrevistados mencionam que, em resposta aos desafios competitivos, as empresas do setor necessitam modernizar o parque industrial e seus produtos, bem como buscar preços competitivos para melhorar sua competitividade e poder enfrentar a concorrência dos artigos importados. Trata-se de buscar os diferenciais que, segundo Barney e Hesterly (2011), conferirão condições competitivas vantajosas. Destacam-se, nas afirmações obtidas, a percepção de que há um crescimento da conscientização para a necessidade de investimento em pesquisas e materiais como forma de alcance dos patamares competitivos em que se encontra o mercado externo. Nota-se, assim, uma correspondência aos preceitos de Porter (2003), Bateman e Snell (2007) e Hamel e Prahalad (2002), sobre a importância da inovação para adaptação às mudanças na demanda dos consumidores e sustentação de vantagens competitivas diante do acirramento da competição e novos concorrentes. Exemplos dessa visão são encontrados em falas como as seguintes:

[...] ano a ano a indústria têxtil de confecção do Brasil, ela tem investimento por volta de 2,5 bilhões de dólares por ano, investimento anual. Ou seja, se não fosse esse investimento, a gente já tinha quebrado mesmo, já tinha entregado os pontos, porque o investimento faz com que você traga equipamentos novos, equipamentos mais modernos, equipamentos mais produtivos, fazendo com que o produto seja mais competitivo (E1).

[...] a gente observa que hoje, cada vez mais o pessoal tem trabalhado porque é preciso tornar competitivo... Então, aqui no Brasil, as indústrias têm trabalhado bastante para isso (E2).

[...] vem modernizando o parque industrial, aumentando sua produtividade e diminuindo a necessidade de mão de obra qualificada maciça nos processos produtivos (E4).

[...] o Brasil terá sua Indústria Têxtil, assim como já ocorrido em outros países europeus, praticamente sua Indústria Têxtil focada na manufatura de produtos diferenciados (alta moda e gamas de público de maior poder aquisitivo), de alto valoragregado e produtos de uso técnico, sendo o mercado das commodities praticamente reservado aos produtos importados, principalmente aos asiáticos (incluindo também produtos confeccionados) (E5).

Há um destaque especial atribuído aos custos com as operações como obstáculos ao desenvolvimento da competitividade do setor têxtil brasileiro, conforme destacam Melo et al. (2007). Exemplos dessa preocupação são encontrados em menções como: 
[...] é o custo Brasil, devido a distâncias, falta de portos, condições, impostos absurdamente altos, então isso não depende da indústria, não depende da fábrica, isso está além da fábrica. Por isso que eu digo, é uma política industrial. Por exemplo, na Índia, que não é o primeiro, é o 2 país do mundo, ela tem o Ministério da Indústria Têxtil (E1).

[...] nossas limitações devido ao nosso tão conhecido Custo Brasil, não vemos condições para que isso ocorra (alcançar primeira colocação como produtores têxteis). Temos que ter claro que a Indústria Têxtil e de Confecção representam indústrias de mão de obra intensiva e, logicamente, com a elevação do nível econômico da população dos últimos anos, este custo torna-se negativo ao aumento de sua atividade, fato este que irá gradativamente ser cada vez mais negativo para atingir estas posições (E5).

Os entrevistados relacionaram esse alto custo cobrado no Brasil com a falta de políticas públicas por parte do Governo e as altas taxas tributárias cobradas em operações industriais:

[...] o custo do produto final nosso é altíssimo, justamente por questão de tributação, dos impostos que são muito altos, seja o produto em si ou o capital humano (E2).

Falta apoio do Governo, principalmente aos médios empresários, que é a maior barreira para o crescimento, e acabamos sofrendo com todas as políticas governamentais (E3).

É o que se encontra também em panoramas destacados por Melo et al. (2007), compartilhados por estudos encontrados em Texbrasil (2015) e ABIT (2015). Na atualidade, o cenário brasileiro apresenta impostos, taxas alfandegárias e tributação elevados que, conforme citado nas entrevistas, fazem com que o custo Brasil torne-se muito alto, em especial para operações industriais, como as que se realizam no setor têxtil. Esse custo atrapalha a competitividade dos produtos nacionais, pois, a partir dos pressupostos de Porter (2003) e Barney e Hesterly (2011), se os importados apresentam melhor custo-benefício para o consumidor, desfrutam de uma nítida vantagem competitiva.

\subsection{OS DESAFIOS DA INOVAÇÃO PARA O SETOR TÊXTIL BRASILEIRO}

Em testemunho de opiniões que compartilham as afirmações de Govindarajan e Trimble (2010), Sparrow (2010), Bowonder et al. (2010) e Tidd, Bessant e Pavitt (2008), as entrevistas revelam que uma grande importância é atribuída à mudança e inovação para acompanhar o mercado de forma competitiva. Em geral, as assertivas convergem para a opinião de que é necessário inovar a todo tempo e acompanhar o mercado, clientes e concorrentes. Os entrevistados, de modo geral, concordam que a tecnologia está diretamente 
ligada a esse crescimento, já que, com ela, consegue-se captar novas formas de produzir, utilizar e diminuir diversos custos. A percepção dos entrevistados, portanto, denota convergência com a de Porter (2003), para os quais o investimento em tecnologia é cada vez mais necessário para o crescimento do setor. Como exemplo de menções a esse respeito, destaca-se o trecho a seguir:

[...] Com certeza a competitividade está relacionada com o nível tecnológico e inovação das Empresas. Não se pode pensar em competir sem estar up to date com o estado da arte em termos de equipamentos (E5).

Considerando a tecnologia como um dos principais pontos de partida para a inovação, conforme afirma Tigre (2006), os entrevistados defendem a adoção de medidas de incentivo para que essa inovação seja concretizada, entendendo que as condições que favorecem o desenvolvimento da inovação tecnológica deveriam ser maiores no Brasil.

[...] A inovação é o principal fator para tornar uma indústria e/ou uma empresa mais competitiva no mercado de atuação? Mas não tenha dúvida, isso é inegável [...]. Então inovação é essencial (E1).

[...] Agora, faltam incentivos sim, recebe, porém, ainda falta (E2).

[...] apesar de a indústria têxtil no Brasil ser uma das maiores empregadoras, ela não recebe incentivos suficientes [...] percebe-se que o Brasil sempre fica atrás em relação a novas tecnologias, restando ao produtor somente a importação de maquinários e processos (E4).

\subsection{A NANOTECNOLOGIA COMO FORMA DE INOVAÇÃO}

Constatou-se a opinião predominante dos entrevistados quanto à concepção de que a nanotecnologia é uma forma de inovação muito eficiente. Ocorreram menções sobre o interesse que esse tema vem despertando em diferentes meios comumente utilizados para o fomento da competitividade empresarial e econômica de um país. Essas assertivas evidenciam a convergência entre a visão dos entrevistados e a proposição de Maine, Lubik e Garnsey (2012) sobre o potencial de criação de valor resultante dos investimentos em nanociência e nanotecnologia. A sensação que os participantes da pesquisa declaram ter, contudo, é de que a indústria brasileira ainda não está muito apta a usar essa tecnologia, visto que o país precisa se desenvolver muito mais em outros aspectos, antes de partir diretamente para as aplicações da nanotecnologia:

[...] a nanotecnologia é aquela que agrega mais valor, mas do jeito que está colocado aqui, como fonte de inovação, ela não é a melhor, ela é uma delas, e é justamente Revista Eletrônica de Estratégia \& Negócios, Florianópolis, v.8, n.3, set./dez. 2015. 
aquela que agrega mais valor. Mas ela é mais difícil, é ela é melhor aplicada [sic]em países mais desenvolvidos do que no Brasil (E1).

[...] Temos que estar atentos a esta tecnologia, visto que é importante sabermos onde a mesma está sendo aplicada, mas é uma inovação necessária no mundo atual (E3).

Os entrevistados compartilham o conhecimento de experiências em que a tecnologia oferece, à indústria, meios de qualificar e melhorar as propriedades naturais dos tecidos, como as fibras artificiais e muitos tipos de beneficiamento relatados por Udale (2009). Também se evidencia o conhecimento das aplicações e consequentes benefícios que a nanotecnologia pode proporcionar à efetividade dos processos e produtos têxteis mencionados por Moreira, Fangueiro e Leal (2012) e Wong et al. (2014). Contudo, apesar de entenderem o potencial de valor agregado conferido à cadeia têxtil pela utilização de nanotecnologia, mencionado por Maine, Lubik e Garnsey (2012), os entrevistados afirmam que há muitas barreiras para que a nanotecnologia seja implementada de primeira mão. Em outras palavras, além dela, há outros modos de obter inovação e competitividade mais tangíveis, e que talvez, com mais investimento, pesquisas e incentivos, então poder-se-ia usar a nanotecnologia.

[...] Não sei se é somente a nanotecnologia nessa questão. Existem tecnologias que deveriam avançar, principalmente na engenharia, que é o campo que a gente tem para pesquisa, também (E2).

[...] A nano é uma consequência, então você pode usar a nano como outro ferramental para você atingir, mas não que ela seja a melhor de todas. É uma delas, talvez seja a mais difícil de obter (E1).

[...] É interessante, mas não é a melhor, por enquanto. Eu acredito que hoje, em razão da necessidade da sustentabilidade e economia de recursos naturais, qualquer novidade nessa área seria mais importante e rentável (E4).

Como principais dificuldades para a adoção da nanotecnologia, foram citados problemas culturais e de custo para sua implementação no setor têxtil.

[...] O custo da nanotecnologia ainda é a maior barreira para uma maior participação, principalmente no campo têxtil (E3).

[...] Acredito que seja devido à falta de pesquisas na área e por conta dos altos custos iniciais de implementação (E4).

Hoje, a nanotecnologia ainda é muito dispendiosa para ser implementada no Brasil. Segundo se nota na fala dos entrevistados, o país deveria investir muito mais em pesquisas acadêmicas e científicas para que o conhecimento na área se desenvolva e o país possa coRevista Eletrônica de Estratégia \& Negócios, Florianópolis, v.8, n.3, set./dez. 2015. 
meçar a ter um olhar mais focado nessa tecnologia. Assim, com investimento em estudo e diminuição de custos, a nanotecnologia seria uma forma viável de tornar o setor têxtil mais inovador e competitivo. Mas ainda não se observa, talvez por questões culturais, a mesma preocupação de autoridades e empresas locais em relação ao que ocorre em outros países:

[...] No meu ponto de vista é cultural. Aplica-se em várias escalas no Brasil. Eu acho que, com isso, o setor têxtil também perde bastante, porque nós poderíamos realmente estar um passo adiante, principalmente quando você vê a Dupont, por exemplo, que trabalha com nanotecnologias, principalmente de acabamentos (E2).

Além dessas dificuldades citou-se a de divulgação e comunicação entre as empresas que necessitam de nanotecnologia e os que a produzem.

Uma melhor comunicação à indústria das aplicações conhecidas a seus produtos. Seminários e divulgações práticas da tecnologia de modo sistemático (E5).

Com base nos dados do Grupo de Trabalho (2015), pode-se afirmar que a Nanotecnologia é, hoje, um dos principais focos das atividades de pesquisa, desenvolvimento e inovação em todos os países industrializados. Porém, a visão dos entrevistados denota uma concordância com Melo et al. (2007), para os quais a conjuntura do país apresenta fatores como altos custos, falta de apoio do governo e falta de incentivos a pesquisas como pontos principais para ainda não se ter a tecnologia como principal fonte de inovação. Embora se entenda, como revelam as entrevistas, que a nanotecnologia seria uma excelente oportunidade para setor têxtil crescer e tornar-se competitivo no país, o Brasil ainda precisa de foco em outras frentes antes dessa oportunidade de desenvolvimento tecnológico.

Em síntese, a despeito do reconhecimento de expressivos benefícios potencialmente decorrentes da aplicação da nanotecnologia à cadeia produtiva têxtil brasileira, os entrevistados, de forma geral, não a vêem como principal forma de inovar, na atual realidade do setor no país, principalmente pela carência de incentivo e iniciativa por parte dos órgãos do governo. É comum a opinião de que é necessário investimento em pesquisa como caminho para que as empresas brasileiras tornem-se mais competitivas perante a concorrência internacional, o que passa pela necessidade da cultura voltada para a inovação mencionada por Sparrow (2010). Além disso, também é necessário despertar a consciência para potenciais vantagens competitivas advindas da adoção de estratégias baseadas na inovação, conforme destacam Bowonder et al. (2010). 


\section{CONSIDERAÇÕES FINAIS}

Com o propósito de conhecer as possíveis contribuições que a nanotecnologia pode trazer à indústria têxtil brasileira como forma de inovação e aumento da competitividade, procurou-se identificar as principais características e benefícios da utilização da nanotecnologia, sua amplitude e alcance de mercado. No setor especificamente enfocado, buscaram-se informações sobre fatos e opiniões relativos à adoção de estratégias de inovação e de uso da nanotecnologia como meio de obter competitividade nas empresas que integram a cadeia produtiva têxtil.

A partir dos estudos realizados sobre os temas tratados (nanotecnologia, indústria têxtil, competitividade e inovação), constata-se que a indústria têxtil está cada vez mais se expandindo em todo mundo, e criando oportunidades de inovação em toda sua cadeia produtiva.

Como forma de competitividade das empresas atuantes nessa indústria estudada, apresenta-se a inovação para, assim, obter diferenciais e apresentar diversas formas de atender a mercados já estabelecidos, ou até mesmo criar novos mercados.

A pesquisa realizada revela indícios de que a nanotecnologia seria uma forma de inovar dentro da empresa e indústria atuante nesse setor, já que ela pode ser utilizada em toda sua cadeia produtiva, trazendo contribuições. Hoje, é o que traz maior valor agregado, porém, além de ser um assunto ainda não conhecido por todo mercado, é uma tecnologia de alto custo, que necessita de incentivos e investimentos constantes que o Brasil ainda não apresenta.

Ainda como resultado da pesquisa, foi possível constatar que há outras maneiras de conseguir ser competitivo na indústria têxtil focando em inovação, porém em um menor patamar do que a nanotecnologia. É necessário, primeiramente, focar em custos, pesquisas e engenharia, desenvolver-se nesses aspectos para, depois, pensar em avançar para a aplicação da nanotecnologia na indústria.

Embora este trabalho possa ser considerado como uma organização de informações, com o potencial de contribuir para o conhecimento de visões de profissionais envolviRevista Eletrônica de Estratégia \& Negócios, Florianópolis, v.8, n.3, set./dez. 2015. 
dos com estudos e atuação relacionados à indústria têxtil, tecnologia e inovação, reconhecese, como limitação, que a abrangência das constatações obtidas está restrita ao universo pesquisado, que não pode ser considerado representativo da visão da maioria. Portanto, a generalização das conclusões apresentadas dependeria de outras pesquisas complementares para a identificação de tendências, com validade estatística. Contudo, entende-se que os objetivos estabelecidos foram atingidos, no que se refere ao que se pretendeu investigar e ao método utilizado.

\section{REFERÊNCIAS}

ABIT - ASSOCIACÃO BRASILEIRA DA INDÚSTRIA TÊXTIL. [2015] Disponível em: < http:// www.abit.org.br/Home.aspx >. Acesso em: 17 set. 2015.

ABIT - ASSOCIAÇÃO BRASILEIRA DA INDÚSTRIA TÊXTIL. Relatório setorial da cadeia têxtil brasileira. São Paulo, v. 3, n. 3, set. 2003.

BARDIN, L. Análise de conteúdo. Lisboa: Edições 70, 2007.

BARNEY, J. B.; HESTERLY, W. S. Administração Estratégica e Vantagem Competitiva. 3. Ed. São Paulo: Pearson Prentice Hall, 2011.

BATEMAN, T. S.; SNELL S. A. Administração: liderança e colaboração no mundo competitivo. São Paulo: McGraw-Hill, 2007.

BBC Brasil. Brasil despenca em ranking de competitividade. 2013. Disponível em: <http://www.bbc.co.uk/portuguese/noticias/2013/05/130530_ranking_competitividade_lgb .shtml>. Acesso em: 03 set. 2015.

BOWONDER, B.; DAMBAL, A.; KUMAR, S.; SHIRODKAR, A. Innovation strategies for creating competitive advantage. Research Technology Management, v.53, n.3, p.19-32, 2010.

BUZBY, J. C. Nanotechnology for food applications: more questions than answers. The Journal of Consumer Affairs, v. 44, n. 3, p. 528-545, 2010.

COLCHESTER, C. Textiles-tendências actuales y tradiciones. Barcelona: Art. Blume 2008.

COSTA, A. C. R; ROCHA, E. R. P. Panorama da cadeira têxtil e de confecções e a questão da inovação. Rio de Janeiro: 2009. Disponível em:

<http://www.bndes.gov.br/SiteBNDES/export/sites/default/bndes_pt/Galerias/Arquivos/co nhecimento/bnset/Set2905.pdf>. Acesso em: 18 nov. 2015.

COUTO, G. G. Nanopartículas de níquel: síntese, caracterização, propriedades e estudo de sua utilização como catalisadores na obtenção de nanotubos de carbono. 2006. 27 f. Dissertação (Mestrado em Química) -Departamento de Química, Universidade Federal do Paraná, Curitiba, 2006.

Revista Eletrônica de Estratégia \& Negócios, Florianópolis, v.8, n.3, set./dez. 2015. 
OLIVEIRA, P. H. de; EPAMINONDAS, M. E. R. Conhecimento, Inovação e Estratégia competitiva: um estudo no setor atacadista da moda. Revista Eletrônica de Estratégia \& Negócios, v. 7, n. 1, p. 82-104, 2014.

DOERING, R. Potential opportunities for nanotechnology in electronics manufacturing. Solid State Technology, 12-15, 2011.

DURAN, N.; MATTOSO, L. H. C.; MORAIS, P. C. de. Nanotecnologia: introdução, preparação e caracterização de nanomateriais e exemplos de aplicação. São Paulo: Artliber Editora, 2006.

ERDOGAN, Y. Nanotechnology in cement \& concrete industry. Cement \& Concrete World, v. 16, n. 94, p. 61-75, 2011.

EXAME. Nanotecnologia para os outros. Disponível em: <http://exame.abril.com.br/ revistaexame/edicoes/0954/noticias/nanotecnologia-outros-505404>. Acesso em: 03 set. 2015.

FESTEL, G.; KRATZER, J. The founding angels investment model - case studies from the field of nanotechnology. Journal of Business Chemistry, v. 9, n. 1, p. 19-29, 2012.

FLICK, U. Uma introdução à pesquisa qualitativa. 3ạ. Ed. Porto Alegre: Artmed, 2009.

FOLHA. Brasil cai em ranking mundial de competitividade e fica em 54익. lugar. Folha de São Paulo, edição de 22/05/2014. Disponível em: <http://www1.folha.uol.com.br/mercado/ 2014/05/1458086-brasil-cai-em-ranking-mundial-de-competitividade-e-fica-no54lugar.shtml. Acesso em: 21 jun. 2015.

GODOY, A. S. Introdução à pesquisa qualitativa e suas possibilidades. Revista de Administração de Empresas, v.35, n.2, p.57-58, mar/abr. 1995.

GOVINDARAJAN, V. TRIMBLE, C. O outro lado da inovação: a execução como fator crítico de sucesso. Rio de Janeiro: Editora Elsevier, 2010.

GRUPO DE TRABALHO criado pela portaria MCT no 252. Programa de Desenvolvimento da Nanociência e da Nanotecnologia do PPA 2004-2007. Disponível em: <http://www.unimuenster.de/imperia/md/content/bioforum/artikel/nanotecbrasil.pdf $>$ Acesso em: 10 out. 2015.

HAMEL, G.; PRAHALAD, C. K. Competindo pelo futuro: estratégias inovadoras para obter o controle do seu setor e criar os mercados de amanhã. 15. ed. Rio de Janeiro: Campus, 2002.

HITT, M. A.; IRELAND, R. D.; HOSKISSON, R. E. Administração estratégica. 3. ed. São Paulo: Cengage Learning, 2015

HOSKISSON, R. E.; HITT, M. A.; IRELAND, R. D.; HARRISON, J. S. Estratégia Competitiva. 2. Ed. São Paulo: Cenage Learning, 2010. 
JOHNSON, J. M. In-depth interviewing. In: HOLSTEIN, J. A.; GUBRIUM, J. F. (Eds.) Handbook of interview research: context $\&$ method. Thousand Oaks: Sage Publications, 2002, p. 103119.

KHADZHIEV, S. N. Nanoheterogeneous catalysis: a new sector of nanotechnologies in chemistry and petroleum chemistry (a review). Petroleum Chemistry, v. 51, n. 1, p. 1-15, 2011.

MAINE, E.; LUBIK, S.; GARNSEY, E. Process-based vs. product-based innovation: Value creation by nanotech ventures. Technovation, v. 32, n. 3, p. 179-192, 2012.

MCTI - MINISTÉRIO DA CIÊNCIA, TECNOLOGIA E INOVAÇÃO. Disponível em: < http:// www. mcti.gov.br/nanotecnologia >. Acesso em: 17 set. 2015.

MELO, M. O. B. C.; CAVALCANTI, G. A.; GONÇALVES, H. S.; DUARTE, S. T. V. G. Inovações Tecnológicas na Cadeia Produtiva Têxtil: análise e estudo de caso em indústria no nordeste do Brasil. Revista Produção Online UFSC, Santa Catarina, v. 7, n. 2, ago., 2007.

MOREIRA, A. P.; FANGUEIRO, R.; LEAL, N. S.. Estratégias de comunicação de produtores de fibras funcionais para artigos têxteis: a corrente de comunicação como estratégia para incentivar novos produtos e ideias na cadeia têxtil. Revista Eletrônica de Estratégia \& Negócios, v.5, n.1, p.67-87, jan./abr. 2012.

PORTER E., M. Competição: Estratégias Competitivas Essenciais. 10. Ed. Rio de Janeiro: Campus, 2003.

SPARROW, P. Cultures of innovation. Management Today, abr. 2010.

STAMPFLI, N.; SIEGRIST, M.; KASTENHOLZ, H. Acceptance of nanotechnology in food and food packaging: a path model analysis. Journal of Risk Research, v. 13, n. 3, p. 335-347, 2010.

TEXBRASIL. Disponível em: <http://www.texbrasil.com.br/texbrasil/ SobreSetor.aspx?tipo=15\&pag=1\&nav>. Acesso em: 20 jun. 2015.

TIDD, J; BESSANT, J. R; PAVITT, K. Gestão da Inovação. 3. Ed., Porto Alegre: Bookman, 2008.

TIGRE, P. B. Gestão da inovação: a economia da tecnologia no Brasil. 2ª. Ed., Rio de Janeiro: Campus, 2006.

TOMAS, H. E. O mundo nanométrico: a dimensão do novo século. São Paulo: Oficina de Textos, 2009.

UDALE, J. Fundamentos de design de moda: tecidos e moda. Porto Alegre: Bookman, 2009.

VENÂNCIO, D. M.; ANDRADE, D.; FIATES, G. G. S. Inovação em serviços: Um estudo bibliométrico da produção científica no Portal Capes até setembro de 2013. Revista Eletrônica de Estratégia \& Negócios, Florianópolis, v.7, n.1, jan./abr.2014.

WRIGHT, P.; KROLL, M. J.; PARNELL, J. Administração estratégica: conceitos. São Paulo: Atlas, 2007.

Revista Eletrônica de Estratégia \& Negócios, Florianópolis, v.8, n.3, set./dez. 2015. 
NANOTECNOLOGIA: INOVAÇÃO PARA A COMPETITIVIDADE NA CADEIA PRODUTIVA TÊXTIL BRASILEIRA

Adilson Caldeira - Ana Cristina Bachur Silva - Camila Marinho Borba - Caroline Petruz - Elis Aniceto

Revista Eletrônica de Estratégia \& Negócios, Florianópolis, v.8, n.3, set./dez. 2015. 